\section{As múltiplas alfabetizações midiáticas}

\section{RESUMO}

Existem pelo menos três tipos de alfabetizações midiáticas, cada uma delas ligada a uma diferente concepção do que nós pretendemos dizer com o termo mídia. A noção de que os mídia são condutores que transmitem mensagens aponta para a necessidade da alfabetização no conteúdo dos mídia. A idéia de que os mídia são diferentes linguagens sugere a necessidade de alfabetização numa gramática midiática, isto é, entender 0 significado das variáveis de produção dentro de cada meio. A concepção dos mídia como ambientes sugere a necessidade de se perceber a influência das características relativamente fixas de cada meio (alfabetização midiática), tanto nas comunicações individuais como nos processos sociais em geral. A alfabetização mediática, em particular, oferece algumas idéias especiais no que se refere as origens, problemas, e possibilidades de um movimento pela alfabetização midiática.

\section{ABSTRACT}

There are at least three different types of media literacy, each linked to a different conception of what we mean by the term media. The notion that media are conduits that carry messages points to the need for media content literacy. The idea that media are distinct languages suggests the need for media grammar literacy, that is, understanding the use of production variables within each medium. The conception of media as environments suggests the need to grasp the influence of the relatively fixed characteristics of each medium (medium literacy), both on individual communications and on social processes in general. Medium literacy, in particular, offers some special thoughts into the origins, problems, and possibilities of the media literacy movement.

\section{PALAVRAS-CHAVE/KEY-WORDS}

- Grámatica Midiática (Media Grammar)

- Tecnologia (Technology)

- Linguagem (Language)
O QUE É ALFABETIZAÇÃo MIDIÁTICA? Discus-sões sobre este conceito usualmente focam atenção em como redefini-lo para adequalo ao nosso atual ambiente midiático.

Menos atenção tem sido dado a diferentes definições sobre a segunda metade da frase.

Afinal de contas, todo mundo sabe claramente o que os media são!

$\mathrm{Na}$ verdade, é a penetração de uma larga quantidade de media - filmes, rádio, televisão, computadores, e assim por diante - que tem estimulado em primeiro lugar o novo debate para reconceituar a alfabetização.

Sim, eu sustento que há menos consenso do que o esperado sobre o que nós queremos dizer com media, do que pesquisadores, pais, e professores podem imaginar.

Também, diferentes formas de pensar sobre os media nos levam a diferentes concepções de competências, ou alfabetizações, do que pode ser desejável para o educado e consciente cidadão.

Neste ensaio eu esboço uma tipologia de múltiplas alfabetizações, baseada em três distintas metáforas do que um meio de comunicação é.

Cada metáfora nos leva a um leque de diferentes questões sobre os media, a diferentes entendimentos sobre pesquisa dos meios, e a uma diferente forma de definir alfabetização midiática básica.

Ainda, os diferentes conceitos dos media descritos aqui não estão totalmente desconectados.

Os modelos visuais incluídos neste artigo, portanto, tentam retratar tanto as diferenças como as relações entre três tipos de conhecimento sobre as mídias.

Tabela 1. Os Elementos do Conteúdo Mídiático 
A metáfora mídia-como-condutores foca a atenção naqueles elementos que se movem de modo relativamente fácil de meio a meio e entre a interação ao vivo e os mídia, tais como:

\author{
idéias \\ temas \\ tópicos \\ informação \\ valores \\ ideologias \\ apelos persuasivos \\ montagens \\ objetos \\ personagens ou papéis \\ ações ou condutas \\ narrativas
}

gêneros (temática ou topicamente definidos)

Questões típicas sobre o conteúdo dos media exploram :

Estrutura/ modelo de elementos dos conteúdos acima referidos

Motivações de produtores do conteúdo

Influência da estrutura da indústria mídiática no conteúdo

Influências políticas e econômicas no conteúdo

Variações da percepção individual e de grupo do conteúdo

Correlações entre conteúdo dos mídia e a realidade Os efeitos do conteúdo

Os tipos de mensagens que raramente ou quase nunca aparecem na mídia mainstream

\section{Conteúdo da alfabetização midiática}

A concepção mais comum de mídia é a de que eles são condutores que contém e enviam mensagens. Esta concepção tem provocado muitas formas de discussão e de estudar o conteúdo da mídia. Dentro desta visão geral, alfabetização midiática básica envolve ser capaz de acessar e analisar mensagens numa variedade de media. Alfabetização de conteúdos toma muitas formas.

Isto inclui estar capacitado a decodificar e decifrar a intenção manifesta da mensagem; explorar as mensagens latentes intencionais ou não; estar consciente de diferentes gêneros de conteúdos; estar consciente das forças culturais, institucionais e comerciais que tendem a levar certos tipos de mensagens enquanto outras são evitadas; e entender que diferentes indivíduos e grupos tendem a "ler" os mesmos "textos" diferentemente.

Como a lista de elementos de conteúdo da Tabela 1 sugere, o conteúdo midiático domina a maioria dos debates e estudos da mídia. No entanto, a visão explícita ou implícita da mídia como condutora é partilhada por muitos críticos e pesquisadores que teriam pouco em comum fora esta visão.

Isto inclui pregadores que condenam a natureza imoral de muitos comportamentos retratados pela TV; ativistas que protestam contra a imagem limitada e estereotipada da mulher, gay, afro-americanos, e outras minorias na mídia; e um amplo leque de pesquisadores que estudam os conteúdos manifestos e latentes nas notícias e entretenimento através de um variado leque de métodos quantitativos e qualitativos.

A importância do conteúdo midiático é mais visível quando outros elementos das comunicações mediadas são ignorados e quando um elemento $\boldsymbol{A}$ é contrastado com um elemento $\boldsymbol{B}$ real ou hipotético:

\section{A vs. B}

ELEMENTO DE CONTEÚDO A VS. ELEMENTO DE CONTEÚDO B Por exemplo:

Conteúdo Violento $X$ Pacífico

Conteúdo Sexual Discriminatório $X$ Igualitário

Reportagem de Rotina $X$ Jornalismo Investigativo Conteúdo Irreal $X$ Realista

Certo gênero $X$ Outro gênero

\section{Figura 1. Análise de conteúdo}

Muito embora a pioneira teoria dos efeitos de transmissão estímulo-resposta tenha sido abandonada há bastante tempo nos círculos acadêmicos dando lugar a métodos mais sofisticados e modelos das sutis influência e transação dos media, a maioria destas visões não se afastou verdadeiramente destas suposições iniciais: 
de que há algo no interior, e de alguma forma separável do medium, que pode ser analisado e estudado. Como Wilbur Schramm (1973), um ícone de um tipo de estudo do conteúdo, afirmou certa vez, "A mensagem é a mensagem, e o meio é o meio" (p. 128).

O foco no estudo do conteúdo da mídia é popular por diversas razões. Uma delas, o conteúdo da mídia - pelo menos em sua forma manifesta - tende a ser o aspecto mais óbvio das comunicações mediadas. Isto torna o conteúdo da mídia importante para o estudo.

Além do mais, as preocupações das abordagens que tratam do conteúdo midiático tendem a focar nos aspectos comunicacionais que não são específicos de uma mídia específica.. Na verdade, a maioria dos seus elementos envolve comportamentos, temas e tópicos que passam facilmente de meio para meio e entre interações mediadas e não mediadas.

Por exemplo, as preocupações mais comuns deste tipo de estudo (por exemplo, violência, discriminação sexual, racismo, preconceito ideológico) incluem tudo que existe na maioria das formas de comunicação, incluindo a interação face a face. Deste modo, numa sociedade saturada de veículos de comunicação, as questões do conteúdo da mídia chamam a tenção de qualquer pessoa que tenha uma forte preocupação com qualquer aspecto da vida social.

Em decorrência do fato de que os elementos do conteúdo midiático podem ser separados, pelo menos analiticamente, dos veículos que os contém, discussões sobre o conteúdo de um mídia podem ser apresentados em qualquer outro meio.

O conteúdo da mídia pode ser facilmente codificado, contado e verbalmente analisado. A facilidade com que cada um pode falar e escrever sobre o conteúdo da mídia, independentemente do meio em que o conteúdo se encontra, o torna um tópico favorito de eruditos da mídia, pregadores, políticos e professores.

Para fixar um cenário que visualize a relação entre o conteúdo da alfabetização de conteúdos e outras formas de alfabetização midiática, eu sugiro usar as letras $A, B, C$, e assim por diante para simbolizar os elementos dos conteúdos da mídia (ver figura 1).

As questões de conteúdo geralmente focam na análise de algum aspecto de conteúdo do elemento $A$, contrastando, explicita ou implicitamente, com um elemento de conteúdo real ou hipotético $B$.

Saber como acessar, interpretar, e avaliar os conteúdos de uma variedade de mídia é um ingrediente essencial para qualquer concepção de alfabetização midiática. Poder-se-ia sustentar, por exemplo, que qualquer cidadão precisa saber bastante sobre notícias para que uma democracia possa funcionar.

Uma alfabetização midiática básica poderia ir além de simplesmente estar se atualizando com as notícias. Também poderia envolver o entendimento de como as notícias são construídas e como fatores políticos, econômicos, e institucionais limitadores podem fazer certas formas de notícias dominar, independentemente do meio através do qual as notícias são comunicadas.

As últimas décadas têm testemunhado um crescimento de uma excelente literatura sobre a análise crítica das notícias que pode facilmente servir de base para a alfabetização midiática das notícias (e.g. Altheide, 1976; Gans, 1979; Hallin,1994; Herman \& Chomsky, 1988; Manoff e Schudson, 1986; Schudson, 1995; Seagal, 1973; Tuchman, 1978). Um argumento poderoso (e de alguma forma relacionado) poderia ser feito em favor de uma compreensão básica de como nossos conteúdos midiáticos servem aos propósitos de uma publicidade explicítica ou implítica (e.g. Branow,1978; Savan , 1994).

No entanto, os temas relacionados ao conteúdo da mídia, por importante que sejam, não esgotam as habilidades básicas que devemos ter com relação aos veículos.

$\mathrm{Na}$ verdade, de alguma forma, a forma mais popular de se estudar os media é não tratar realmente dos veículos. Ou seja, quando o foco é o conteúdo, não se dá muita atenção às características particulares do veículo através das quais as mensagens transportadas são examinadas.

Nas próximas duas seções eu descrevo as concepções dos media que 
sugerem a necessidade por duas formas de alfabetização midiática.

\section{A alfabetização da gramática dos mídia}

Outra concepção dos media envolve ver cada veículo com sua própria linguagem. Esta visão dos media nos leva focar o olhar numa espécie de gramática única de cada medium e as formas através das quais as variáveis de produção de cada veículo - ou que Zettl (1990) chama de aspectos estéticos do medium - interagem com outros elementos. Ao contrário da maioria dos elementos de conteúdo, que passam facilmente de veículo a veículo e da interação não mediada à interação mediada, as variáveis da gramática dos media são peculiares ao veículo. Muito embora se possa exibir violência e discriminação racial na vida real, por exemplo, é difícil "fazer um close up" ou "editar" nas interações diárias. Uma pessoa não pode cantar a harmonia e a melodia sem o auxílio do gravador, nem pode mudar a tipologia numa fala.

A alfabetização midiática básica nesta concepção dos media como linguagem envolve a compreensão e o reconhecimento do largo espectro de variáveis de produção existentes em cada veículo. Assim como envolve o reconhecimento das maneiras através das quais as variáveis são tipicamente utilizadas para tentar moldar a percepção e a resposta às comunicações mediadas. Uma alfabetização mais avançada da gramática envolve o conhecimento de um largo espectro de variáveis em cada veículo, sendo assim capaz de manipular de forma eficiente tais variáveis nas produções de cada veículo, compreendendo as forças culturais e institucionais que tendem encorajar alguns usos gramaticais em vez de outros, e reconhecendo que as respostas às variáveis de produção podem variar individualmente e culturalmente. ${ }^{1}$
Tabela 2. Amostra das variáveis gra máticas para vários veículos

Variáveis de produção podem ser manipuladas dentro de cada meio para alterar a percepção do conteúdo da mensagem:

Mídia Impressa

Tamanho/formato da página

Cor(es) do papel

Espessura do papel

Tamanho do papel

Formato(s) da fonte

Cor (es) da fonte

Uso do itálico/negrito

Tamanho das colunas

Espaçamento

Quebra de parágrafo

Pontuação

Espaçamento em branco

Diagramação do texto

Retrato- fotografia

Enquadramento (close, meio foco, foco profundo)

Ângulo (inferior, normal, superior)

Frontal/ de costas/lateral

Seleção do foco

Profundidade do foco

Lentes (grande angular e teleobjetiva)

Exposição

Abertura do diafragma

Velocidade do obturador

Tipo de filme

Filtro(s)

Dupla exposição

Equilíbrio de cores

Contraste

Tipo do papel

Crooping

Tamanho/formato da imagem

Rádio/Áudio

Tipos de microfones

Perspectiva sonora

Volume eletrônico

Timbre eletrônico

Filtro (s) de freqüência

Fade up/ fade out / cross fade 


\section{Multitracking \\ Segue/ silêncio \\ Eco \\ Mudanças rápidas \\ Áudio de fundo \\ Separação de canal \\ Equilíbrio de canal}

\section{TV/Filme}

(as referidas variáveis da fotografia)

(as referidas variáveis do som)

Fade visual de abertura e encerramento

Cortes

Dissolução

Corte transversal

Comprimento dos cortes

Zooms $x$ dollies

Panorâmicas $x$. trucks

Subidas/descidas

Movimento da câmera

Tomadas objetivas $x$ Subjetivas

Imagens divididas/imagem múltipla Foco rack

Foco follow Justaposição de som e imagem

A tabela 2 descreve algumas das variáveis gramaticais que podem ser manipuladas em alguns tipos de mídia para criar certas impressões. Como observado, algumas variáveis operam em mais de um medium. A televisão e o cinema incorporaram algumas das variáveis da fotografia e do áudio.

Quando a fotografia e a imprensa ou o cinema e a imprensa são mesclados (como nas revistas ou nos títulos dos filmes), muitas variáveis em mais de uma das colunas entram em ação. Programas de computador e websites estão incorporando cada vez mais muitas das variáveis de texto, fotografia, som e movimento. Mesmo assim, e apesar do cruzamento de variáveis, cada veículo tende a oferecer sua forma única de mesclar as variáveis. Mesmo a televisão e o cinema, que estão listados juntos na tabela por simplicidade, atingem o mesmo efeito (como é o caso do efeito de dissolver) através de meios físicos variáveis, e cada um deles tem algumas variáveis que não são partilhadas com o outro (como é o caso dos efeitos de largo espectro disponíveis na TV).

Ao contrário da alfabetização dos conteúdos midiáticos, a alfabetização da gramática dos media exige alguma compreensão da especificidade operacional de cada veículo.

Não há espaço aqui para discutir os usos das muitas variáveis dos muitos veículos. Em decorrência, para ilustrar o tipo de conhecimento que a alfabetização da gramática dos media exige descreverei algumas variáveis visuais muito básicas que operam num programa de televisão ou cinema típico. O uso seletivo de close ups, planos curtos e planos longos pode alterar as percepções das seqüências ficcionais e não ficcionais.

O enquadramento das tomadas geralmente segue os padrões culturais das distâncias interpessoais das interações da vida real (Meyrowitz, 1986). As tomadas de close up estimulam as distâncias de intimidade e encorajam os espectadores a terem uma conexão pessoal com a pessoa fotografada. Geralmente, o principal personagem num programa ou num filme é a primeira pessoa vista em close ups freqüentes. Pessoas vistas a maiores distâncias muito provavelmente serão percebidas em termos de seus papéis sociais.

A alfabetização dos media, então, precisa incluir a consciência do fato de que os espectadores podem reagir diferentemente a atos violentos dependendo da forma de como os criminosos e as vítimas são fotografados. Da mesma forma, a consciência do espectador da gramática do veículo lhe permitirá mais do que a outros observar como as seqüências de não ficção (por exemplo notícias e documentários) são cuidadosamente realizadas para parecerem não artesanais, mas simplesmente reais - o que Gaye Tuchman (1978) chama de criação da "aura da representação".

Por exemplo a alfabetização da 
gramática dos media permite observar que, enquanto algumas pessoas que são objeto do noticiário na televisão e que aparecem em close ups, isso raramente ocorre com os jornalistas (a fim de manter a impressão de uma objetividade impessoal).

Os ângulos das câmeras tendem a ser utilizados de forma muito particulares. As tomadas de ângulo baixo (quando se foca o sujeito acima) são freqüentemente utilizadas para sugerir poder e autoridade, muito embora tais ângulos baixos em casos extremos possam ser utilizados para abalar a imagem de importância de alguém.

As tomadas num mesmo nível são tipicamente utilizadas para sugerir que alguém é o seu "igual" ou de um mesmo "nível", o que explica por que esta é outra técnica tipicamente utilizada por jornalistas em suas coberturas. Tomadas do alto (câmeras sobre o sujeito) são tipicamente utilizadas para sugerir que alguém é pequeno ou fraco.

Tomadas de ângulo aberto tendem a ampliar a aparente distancia entre o frontal e o que está distante enquanto que ângulos longos (telefoto) tendem a comprimir o frontal com o que está a distância. Notícias sobre engarrafamento na auto-estrada por exemplo tipicamente utilizam ângulos longos para dar a impressão de que os carros se chocaram. Em contraste, os anúncios de carros tipicamente utilizam ângulos largos para impressionar os leitores com o interior espaçoso dos veículos e para transmitir o apelo de uma larga estrada a sua disposição.

A alfabetização da gramática dos mídia poderia ir além destas variáveis básicas para despertar a consciência de como a manipulação das variáveis de produção pode sutilmente sugerir e influenciar a percepção do público sobre pessoas, lugares e eventos.

A alfabetização da gramática dos media poderia incluir temas de como as variáveis da gramática visual podem ser usadas para guiar a atenção do público (através da estrutura da edição, foco de seleção primária e foco de profundidade); de como se encoraja a justaposição de um lado versus o outro nos filmes de guerra, notícias e documentários (através do posicionamento da câmera, enquadramento das tomadas, movimento da câmera versus o movimento das lentes e rotação); descrever a população de um certo país como integrantes de uma massa humana em oposição a indivíduos noutra (através de tomadas longas); descrever algumas fontes de informação como estáveis e com credibilidade (com tomadas de média distância), e outras fontes como instáveis, ameaçadoras, e sem credibilidade (com câmeras tremendo ou close ups extremos, nos quais qualquer movimento do corpo dá a sensação de querer escapar à vigilância da câmera); e assim por diante.

A alfabetização da gramática dos media deveria também envolver o impacto das variáveis dos media que não são facilmente vistas, como o impacto dos elementos sonoros, que incluem diferentes perspectivas de som (o equivalente auditivo das diferentes tomadas), diferentes padrões de coletas de sons em microfones e filtros de equalização do som.

O impacto da gramática da mídia é mais visível quando um elemento de conteúdo, $A$, é mantido constante e uma variável gramatical contrasta com outra.

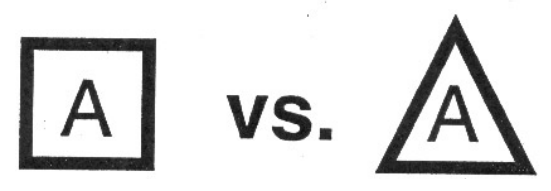

VARIÁVEL GRAMATICAL VS. VARIÁVEL GRAMATICAL

Por exemplo:

ASSASSINATO

Mostrado desde a perspectiva da vítima $x$ a perspectiva do assassino

\section{EXECUTIVA FEMININA}

Retratada como "profissional", com tomada de ângulo médio $x$. "intimidade", close-ups 


\section{RUA EM BAGDÁ}

Multidão é mostrada com tomada de cena em primeiro plano $x$. visão "espaçosa" com a grande angular

Figura 2. Análise da gramática

Naturalmente, não deve haver uma manipulação significativa das variáveis gramaticais dos media sem que haja conteúdo disponível para ser trabalhado. No entanto, a gramática é mais visível quando um elemento de conteúdo é mantido constante. Na figura 2, portanto, as preocupações gramaticais são representadas esquematicamente ao se mostrar um determinado elemento de conteúdo $\mathrm{A}$ dentro de dois polígonos diferentes (um quadrado versus um triângulo) que são utilizados para representar as variáveis gramaticais.

As gramáticas dos media tendem a receber significativamente menos atenção que o conteúdo dos media por várias razões. Uma delas, muitas pessoas simplesmente não estão conscientes do largo espectro das variáveis de produção que são utilizadas, a maior parte do tempo, nos veículos de que deles se valem. Os produtores, afinal de contas, geralmente querem que as audiências estejam conscientes dos elementos do conteúdo, mas não dos elementos gramaticais.

rodutor de televisão ou de cinema preferiria que os membros da audiência conscientemente sentissem empatia por um personagem, mais do que estarem conscientes do uso prolongado de closeups.

Da mesma forma, os editores de um jornal de prestígio não querem que seus leitores considerem que uma porção da credibilidade de um jornal seria perdida se as mesmas matérias fossem publicadas numa tipologia e formato diferentes.

Ironicamente, portanto, o poderoso conteúdo e a poderosa gramática têm efeitos opostos na consciência da audiência: quanto mais efetivos forem os conteúdos midiáticos, mais consciente estará a audiência dos mesmos e mais sobre eles refletirá. Quanto mais efetivos forem os elementos gramaticais dos media, menos consciente dos mesmos estará um membro da audiência.

Mesmo aqueles que estudam os media freqüentemente evitam escrever e falar sobre a gramática dos media em decorrência da dificuldade em fazer uma descrição da gramática distinguindo-a do meio de produção tornando-a um meio de descrição. Os elementos da gramática dos media demandam mais tradução do que os elementos de conteúdo dos media, e não se pode nunca estar certo se um elemento da audiência está consciente das variáveis que sendo descritas.

Por exemplo, eu considero fácil dizer a você aqui em palavras que no filme Wall Street, Bud Fox, o jovem corretor interpretado por Charlie Sheen, tornou-se eventualmente prisioneiro dos mesmos jogos das altas finanças que the tinham dado a sensação de poder (uma descrição de conteúdo).

No entanto, se eu tentar descrever aqui como este tema de conteúdo é reforçado através das mudanças sutis das tomadas do filme, incluindo o uso no momento mais dramático de uma combinação sutil de movimentos zoom-in da câmera em Sheen, fazendo parecer que os prédios de Wall Street que estavam atrás do personagem estivessem desabando sobre ele enquanto ele ainda estava de pé, faria leitores não familiarizados com o impacto visual de tais técnicas de comunicação sentirem-se perdidos.

A forma mais interessante e clara de explicar estas técnicas seria descrevê-las (talvez repetidamente, e vagarosamente) na tradicional forma de apresentação. ${ }^{2}$

Embora aqueles que não têm um treinamento formal em técnicas de produção dos media estejam freqüentemente inconscientes das mesmas, logo que se aprende sobre as variáveis 
gramaticais elas tornam-se difíceis de não serem consideradas. As variáveis listadas na tabela 2 são claramente visíveis ou audíveis tão logo uma pessoa saiba vêlas ou ouvi-las. Ainda mais desafiadora é a terceira concepção de alfabetização midiática descrita na próxima seção e que envolve a concepção dos aspectos menos disponíveis das comunicações mediadas dos espaços.

\section{Alfabetização midiática}

Uma terceira concepção dos media afirma que cada medium é um tipo de ambiente que possui características relativamente fixas que influenciam a comunicação numa maneira particular - apesar da escolha dos elementos de conteúdo e apesar da manipulação das variáveis de produção. Esta interpretação é freqüentemente associada a Marshall McLuhan (1964) mas outros ainda antes de McLuhan e muitos ainda depois dele também desenvolveram aspectos desta que eu chamo de "teoria do meio" (Meyrowitz, 1985, pp.16-23;1994).

Eu uso singular, meio, porque ao contrário da maior parte das teorias dos media, este entendimento foca sobre as características particulares de cada veículo. A Tabela 3 lista uma amostra de características que pode ser usada para distinguir um meio de outro (por exemplo, rádio versus televisão), ou para mostrar como um tipo geral de meio é diferente de outro tipo de meio ( por exemplo, a mídia eletrônica versus a mídia impressa).

A alfabetização midiática envolve a compreensão de como a natureza do meio condiciona aspectos chaves da comunicação tanto ao nível micro como macro, como é o caso da sociedade.

A alfabetização midiática ao nível micro por exemplo, poderia nos levar a compreensão de porque um certo tipo de interação (por exemplo, contatar alguém para namorar; terminar uma relação de intimidade; inquirir sobre uma vaga de emprego; vender um certo produto; negociar um tratado de paz) pode funcionar diferentemente dependendo da forma de comunicação (face a face, telefone, carta, correio eletrônico, etc.).

Tabela 3. Amostra de variáveis do meio

A análise do meio foca atenção naqueles aspectos relativamente fixados de um dado meio (ou de um tipo geral de mídia) que torna uma certa comunicação única e distingue-a de outros veículos e da interação face a face.

Tipo de informação sensitiva transportada; unissensorial ou multissensorial (visual, oral, olfativa, etc)

A forma da informação em de cada sentido (p.ex. figura x palavra escrita; clique da máquina vs. voz)

grau de definição, resolução, fidelidade (p.ex. uma voz no rádio está mais próxima de uma voz ao vivo do que um close-up de uma face na TV)

unidirecional $x$ bidirecional $x$ multidirecional (p.ex. rádio $x$ telefone $x$ conferência por computador on-line)

simultâneo x seqüência bidirecional (p.ex. ouvir a resposta de outra pessoa quando ela fala ao telefone $x$ CB turn taking)

rapidez e medida de rapidez na codificação, disseminação, e decodificação

o grau de facilidade / dificuldade para aprender a codificar e decodificar e numerar e tipificar os estágios da aprendizagem

(p.ex. aprender a ler vs. aprender a escutar rádio) 
a média entre a dificuldade de codificar e a dificuldade em decodificar

requerimento físico para engajar o meio (Alguém tem que estar em um certo lugar, pegar algo, parar, olhar numa certa direção, usar uma iluminação especial, parar a interação ao vivo, etc.?)

grau e medida de manipulação humana (p.ex. pintar um quadro x tirar uma foto)

amplitude e a natureza da disseminação (p.ex. quantas pessoas podem receber a mesma mensagem ao mesmo tempo)

Muitas pessoas, por exemplo, podem evitar o uso do telefone para pôr fim a uma relação de intimidade porque, com o telefone, a mensagem verbal pode ser exagerada em decorrência da tonalidade vocal emocional, e o falante é interrompido e influenciado pelas palavras e sons da outra pessoa.

Uma chamada tipo "o querido John está ao telefone" é freqüentemente e inerentemente paradoxal. Uma vez que o telefone oferece comunicação vocal simultânea e bidirecional, ele tende a manter uma intimidade informal e uma relação fluida mesmo quando se está tentando romper tal relacionamento. Uma carta que comece com Querido John, no entanto, permite que só um fale sem revelar uma vocalização emocional ou que seja forçado a se defrontar com interrupções ou respostas do outro. Além disso, ao contrário de uma chamada telefônica, uma carta permite ao remetente escrever e rescrever o texto. Por razões similares o telefone é muito melhor que uma carta para iniciar uma relação de intimidade.

Sua simulação de uma conversação próxima permite o teste da intimidade através do canal vocal sem a intensidade inicial da proximidade do corpo, da visão e do cheiro.

Ao nível macro a alfabetização midiática envolve a compreensão ampla de como um novo meio pode levar a amplas mudanças sociais. Por exemplo, a teoria do meio ao nível macro explora questões tais como a alteração que pode ocorrer na natureza e no tipo das situações sociais, nas relações entre as pessoas, e o fortalecimento ou enfraquecimento das várias situações sociais em decorrência da adição de um novo meio à matriz dos veículos existentes.

Os ambientes dos veículos são mais visíveis quando os elementos de conteúdo são mantidos constantes e se olha para além das opções gramaticais existentes em cada um, percebendo-se então as diferenças entre utilizar um meio em vez de outro meio (ou meio algum).

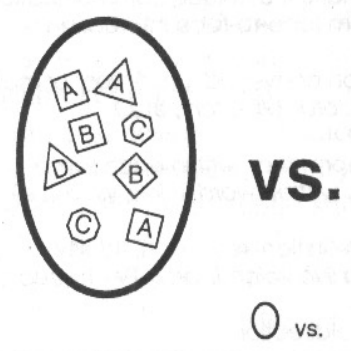

AMBIENTE DO MEIO

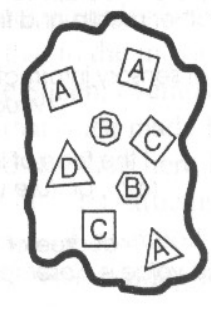

AMBIENTE DO MEIO
Por exemplo:

e-mail $x$ telefonema

debate político no rádio $x$ na TV notícia via TV $x$ jornal

discussão política na rede de televisão $x$

$T V$ comunitária interativa educação numa "cultura condicionada pela impressão" x numa "cultura eletrônica" (também: qualquer meio vs. face a face)

No nível micro, que trata de uma situação específica, a análise do meio vê as implicações entre escolher um meio versus outro meio por uma comunicação determinada. No nível macro, a análise do meio no nível social explora como o amplo uso de um novo meio leva a amplas mudanças sociais.

Figura 3 Análise do meio

Por exemplo a alfabetização 
midiática ao nível macro pode envolver a compreensão de teorias sobre (a) as formas nas quais o amplo uso de telefone mudou os rituais de sedução e as práticas de negócio em geral, incluindo o declínio e a mudança do papel da redação de cartas; (b) as formas através das quais a mídia dominante alterou as concepções sociais sobre o que significa ser educado e competente; (c) se a difusão da televisão, com sua apresentação de sons e imagens de outros distantes, provocou atenção crescente no aparecimento no estilo e nos detalhes da intimidade de figuras públicas; (d) se o uso crescente de mídia eletrônica insensível ao localismo reduziu o significado das fronteiras nacionais e estimulou o processo de globalização; e (e) se o uso crescente da internet com suas inúmeras alternativas e fontes de informação incluindo fatos históricos que rotineiramente são excluídas de matérias dos veículos de jornalismo tradicionais, forçará as organizações de notícia dominantes a alterarem suas práticas de reportagem a fim de manterem a sua credibilidade com o público.

A análise do meio não sugere que os veículos surgem espontaneamente. A alfabetização midiática envolve também consideração de como as forças política econômica e social encorajam o desenvolvimento de alguns meios em vez de outros.

É também significante a pergunta de porque certas formas de veículos diversificados evoluem. Porque, por exemplo, a televisão desenvolveu-se como um meio de massa unidirecional em vez de tornar-se um meio comunitário interativo? Estas análises poderiam facilmente estar ligadas às discussões sobre a natureza comercial de nosso sistema de comunicação e seus elos com as elites corporativas governamentais.

Como a figura 3 indica, a análise do meio envolve comparação explícita ou implícita de um meio de comunicação com outro meio de comunicação (ou com interação não mediada). Devido ao fato que é impossível para um meio ter qualquer influência sem conteúdo, e porque a maior parte das mensagens dos veículos também envolve a manipulação consciente ou inconsciente de variáveis gramaticais, cada ambiente midiático contem elementos de conteúdo (letras) e elementos gramaticais (polígonos).

A teoria dos meios é a menos comum forma de análise da mídia. Isso decorre devido ao fato de que o ambiente criado por um meio é muito menos observado diretamente do que o conteúdo e a gramática dos veículos. O ambiente do meio é mais visível quando um meio está começando a ser usado por uma porção significante da população.

Por exemplo, as discussões correntes sobre o cyberspace geralmente apóiam a perspectiva da teoria dos meios ao afirmar que cada meio é um novo tipo de "lugar" social e cuja influência não pode ser reduzida ao conteúdo das mensagens que fluem através da rede. Tão logo uma nova geração nasça num mundo onde o uso da web é amplo, a consciência do ciberespaço como um novo ambiente social sem dúvida nenhuma diminuirá. Ironicamente, portanto, o ambiente de um meio é mais invisível quando sua influencia é mais ampla.

\section{Sumário e conclusão}

Este artigo sugeriu que existem pelo menos três diferentes tipos de alfabetização midiática, cada um deles ligado à diferente concepção dos media. A idéia que os media são condutores que nos trazem mensagens sugere a necessidade de uma alfabetização midiática de conteúdo. A noção de que os media são linguagens com gramáticas distintas destacam a necessidade da alfabetização midiática das variáveis de produção (alfabetização midiática gramatical). A concepção dos media como ambientes nos alerta da necessidade de compreendermos a influência das 
características relativamente fixas de cada nos níveis micro e macro ou de cada tipo de meio (alfabetização dos meios).

Embora a terceira concepção dos meios seja a menos comum na atualidade, ela oferece algumas idéias especiais aos interessados na alfabetização midiática. A alfabetização midiática no nível macro por exemplo nos dá uma forma de compreender como a mudança das formas de comunicação oral à impressa apoiou novas instituições educacionais e práticas educacionais, que estão agora elas mesmas sendo reformuladas em decorrência do acréscimo de inúmeros outros veículos eletrônicos- o que nos leva a pensar em novas formas de alfabetização.

Ironicamente, a consciência da influência de um veículo leva a terse idéia dos fatores que tornam difícil muitas pessoas perceberem este nível de influência. A compreensão das características de um novo veículo é prejudicada por exemplo pela tendência de descrever-se os novos media usando conceitos retirados dos media mais antigos. Este fato causa crítica de alguns a terminologia que eu também utilizei neste artigo.

O uso do termo alfabetização referese a habilidades como a variedade de veículos e o uso do termo textos referese ao conteúdo dos media não textuais, por exemplo tornando isso ainda mais difícil para muitas pessoas discernirem as diferenças entre os veículos do que a perspectiva da teoria dos meios tenta destacar.

Ver televisão por exemplo tem muito pouco a ver com a alfabetização tradicional (Meyrowitz, 1985, pp.73-114). Televisão é principalmente um sistema de apresentação analógico enquanto que a informação textual é discutível e digital.

As crianças são capazes de ver televisão muito antes de poderem aprender a ler além disso, embora uma criança típica precise aprender a ler livros simples antes de livros mais complexos, há pouca programação adaptada ao horário do sono, que exige que uma criança veja um programa infantil como Mr. Rogers' Neighborhood antes de ver outro como NYPD Blue.

Crianças em tenra idade podem não entender televisão da mesma forma que os adultos (assim como eles podem processar eventos ao vivo diferentemente), mas a televisão não possui aquele tipo de aparelho de seleção que os livros possuem. Usando a noção de alfabetização para descrever engajamentos com todos os veículos tende a obscurecer o fato de que existem diferentes atividades requeridas para o manuseio de diferentes veículos.

A teoria dos meios ao nível macro também oferece uma forma de explicar porque nossas escolas parecem estar agora em crise perpétua. Até recentemente, o sistema escolar desempenhava um papel primário de dar às crianças acesso à informação social geral e ensinar a elas as habilidades básicas que seriam necessárias para se obter acesso às experiências não locais ao longo do resto de suas vidas alfabetização do texto.

As novas e variadas formas de ganhar acesso à informação que dispensam a leitura enfraqueceram agora o poder informacional da escola e diminuíram os incentivos de aprender a ler e escrever bem. Muitas escolas agora sentem as necessidades de redobrarem seus esforços para ensinar as habilidades tradicionais da alfabetização, enquanto tentam ajudar os estudantes a processarem a informação que eles recebem através da mídia não textual. Assim as equipes adicionais, o tempo e os recursos que seriam necessários para trabalhar nessas duas frentes raramente surgem.

Assim, enquanto as escolas lutam para fazer mais a mídia não textual ameaça a estrutura básica do sistema escolar e autoridade tradicional dos professores. 0 sistema que separava os estudantes por idade cronológica desenvolveu-se somente 
com o avanço da alfabetização impressa (Meyrowitz, 1985, pp.258-265).

O sistema estava baseado no pressuposto de que o máximo que uma criança conhece pode estar intimamente correlacionado com a sua idade e a sua habilidade de leitura e que o professor sempre sabe mais que o jovem estudante (Meyrowitz, 1985; Papet, 1993).

$\mathrm{O}$ vasto leque de experiências que as crianças agora possuem através de veículos não impressos torna a idade e a habilidade de leitura fatores muito menos decisivos no conhecimento da criança muito freqüentemente dão aos jovens experiência com tópicos e temas que são não familiares aos seus professores.

Ironicamente, portanto a perspectiva da teoria dos meios clarifica um dos paradoxos plenos de perplexidade do movimento em prol da alfabetização midiática: porque há tantos esforços sendo feitos para incorporar a alfabetização midiática no currículo das escolas, e porque tão pouco sucesso na implementação destes programas foi até agora obtido.

O modelo de múltiplas alfabetizações midiáticas aqui descritas não exige um conjunto finito de saberes que tornam alguém mídia alfabetizado, e que é irreal esperar que um programa qualquer de alfabetização midiática possa ensinar tudo que nós pudéssemos sonhar que crianças e adultos soubessem sobre os veículos.

No entanto, uma consciência mais ampla destes três tipos de alfabetização midiática pode promover habilidades de cidadão entenderem e participarem mais intensamente de uma sociedade que se vê saturada pelos media .

\section{Notas}

* Joshua Meyrowitz (PhD, New York University, 1979) é professor no Departamento de Comunicação na University of New Hampshire. Seus interesses de pesquisa incluem a teoria dos meios e análise crítica das notícias. 0 autor agradece Candice Leonard, Karen Webster, Renée Hobbs, Julie Weiss,
Peter Schimitd, e três revisores anônimos por suas sugestões ao primeiro rascunho. Também agradeço a inestimável assistência em design gráfico oferecida por Scott Williams dos Serviços de Instrução da UNH. Este texto foi publicado originalmente no Journal of Communications, 48(1), Winter 1998, 96-108 e é aqui reproduzido com a autorização do autor.

1 Pode-se também utilizar o processo de produção como um meio de obter a consciência inicial das variáveis de conteúdo e de produção. Meu antigo aluno, Karen Webster, agora estudante de pós-graduação da Universidade de Utah, demonstrou isso em seu estudo sobre a produção das notícias com alunos da quarta e quinta séries do Oyster River Media Education Project de 1990 a 1993. (Webster \& meyrowitz, 1995)

2 A expansão das publicações na web poderá fazer surgir uma nova pesquisa sobre gramática e publicações, porque, partindo do pressuposto que os temas relacionados a copyright e uso adequado dos materiais poderão ser resolvidos,, artigos na web podem conter amostras de som e imagens de temas que estão sendo estudados. Esta possibilidade é um exemplo de um argumento "meio", que surgiu a partir da terceira metáfora discutida neste ensaio.

\section{Referências}

ALTHEIDE, D.L. Creating reality: How TV news disorts events. Beverly Hills, CA: Sage, 1976.

BARNOUW, E. The sponsor: Notes on a modern pontentate. New York: Oxford University Press, 1978.

GANS, H.J. Deciding what's news. New York: Vintage, 1979.

HALLIN, D. We keep America on top of the world: Television journalism and the public sphere. New York: Routledge, 1994.

HERMAN, E. S. e CHOMSKY, N. Manufacturing consent : The political economy of the mass media. New York: Pantheon, 1988.

MCLUHAN, M. Understanding media: The extensions of man. New York: Signet, 1964.

MANOFF, R.K. e SCHUDSON, M. (eds.) Reading the news. New York: Pantheon Books, 1986. 
MEYROWITZ, J. No sense of place: The impact of eletronic media on social behavior. New York: Oxford University Press, 1985.

Television and interpersonal behavior: Codes of percepcion and response. In G. Gumpert \& R. R. Cathcart (Eds.), Inter/Media: Interpersonal communication in a media world (3rd. Ed.,pp.253-272). New York: Oxford University Press, 1986.

Medium theory. In D. Crowley \& D. Mitchell (Eds.) Communication theory today (pp. 50-77). Cambridge, England : Polity Press, 1994.

PAPERT, S. The Children's machine: Rethinking school in the age of the computer. New York: Basic Books, 1993.

SAVAN, L. The Sponsored life: Ads, TV, an Amarican culture. Philadelphia:Temple University Press, 1994.

SCHRAMM, W. Men, messages, and media: A look at human communication. New York: Harper \& Row, 1973.

SCHUDSON, M. The power of news. Cambridge, MA: Harvard University Press, 1995.

SIGAL, L. Reporters and officials. Lexington, MA: Heath, 1973.

WEBSTER, K. e MEYROWITZ, J. (1995, July/August). Whose views make news? Cable in the classroom, pp.10-11.

ZETTL, H. Sight-sound-motion: Applied media aesthetics (2a ed.). Belmont, CA: Wadsworth, 1990. 